\title{
An Interdisciplinary Approach to Optimize the Care of Transitioning Adolescents and Young Adults with CKD
}

\author{
Maria Esther Diaz-Gonzalez de Ferris ${ }^{\mathrm{a}}$ María de Lourdes Díaz-González de Martínez ${ }^{\mathrm{b}, \mathrm{c}}$ \\ Angelica María Díaz-González de Velázquez ${ }^{\mathrm{d}}$ Antonio Díaz-González Borja ${ }^{\mathrm{e}}$

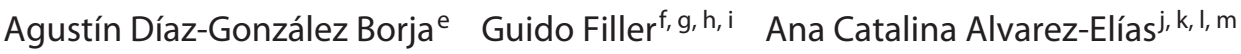 \\ Vicente Díaz-González Borjan ${ }^{\text {n }}$ o
}

\begin{abstract}
aDepartment of Pediatrics, The University of North Carolina at Chapel Hill, Chapel Hill, NC, USA; bscuela de Biotecnología, Universidad Mexicana del Estado de Mexico (UNIMEX), Mexico City, Mexico; ${ }^{\complement}$ Ciencias de la Salud y Metodología de la Investigación, Escuela Preparatoria Oficial Anexa a la Normal de Cuautitlán-Izacalli, Estado de México, Mexico; dSecretaría de Educación Pública, Mexico City, Mexico; 'Díaz-González Borja Centro de Cirugía, Obesidad, Medicina Primaria e Integral, Estado de México, Mexico; fDepartments of Paediatrics, University of Western Ontario, London, ON, Canada; ${ }^{9}$ Departments of Medicine, University of Western Ontario, London, ON, Canada; ' hepartments of Pathology \& Laboratory Medicine, University of Western Ontario, London, ON, Canada; 'Lilibeth Caberto Kidney Clinical Research Unit, London, ON, Canada; ${ }^{j}$ Child Health Evaluative Sciences, The Hospital for Sick Children, Toronto, ON, Canada; ${ }^{k}$ Institute of Health Policy Management and Evaluation, University of Toronto, Toronto, ON, Canada; 'Unidad de Investigación y Diagnóstico en Nefrología y Metabolismo Mineral Óseo,

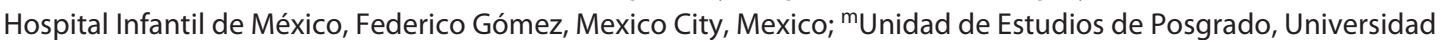

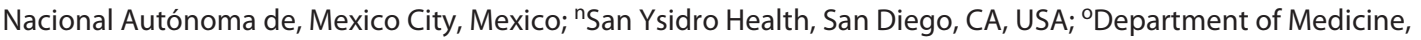
Universidad Autónoma de Guadalajara, Guadalajara, Mexico
\end{abstract}

\section{Keywords}

Health-care transition - Self-management adolescents . Young adults · Chronic kidney disease · CKD · End-stage kidney disease

\begin{abstract}
Adolescents and young adults (AYAs) with CKD or end-stage kidney disease (ESKD) have unique medical, dental, psychosocial, neurocognitive, and academic needs and require close interdisciplinary collaboration to optimize their care. The etiology of CKD in AYAs is diverse compared to older adults. With their continuously improved survival, AYAs must start preparation for health-care transition (HCT) from pediatric- to adult-focused health care in the pediatric setting and it must continue at the adult-focused setting, given
\end{abstract}

that their brain maturation and self-management skill acquisition occur until their mid-20s. While the growth and physical maturation of most visible body parts occur before 18 years of age, the prefrontal cortex of the brain, where reasoning, impulse control, and other higher executive functions reside, matures around 25 years of age. The HCT process must be monitored using patient- and caregiver-measuring tools to guide interventions. The HCT process becomes more complex when patients and/or caregivers have a language barrier, different cultural beliefs, or lower literacy levels. In this article, we discuss the unique comorbidities of pediatriconset CKD/ESKD, provide information for a planned HCT preparation, and suggest interdisciplinary coordination as well as cultural and literacy-appropriate activities to achieve optimal patient outcomes.

(c) 2021 S. Karger AG, Basel

$\begin{aligned} & \text { karger@karger.com } \\ & \text { www.karger.com/bpu }\end{aligned}$
Karger ${ }^{\prime /}$

Maria Esther Diaz-Gonzalez de Ferris

UNC at Chapel Hill, 7021 Burnett Womack Chapel Hill NC 29599-7155 (USA)

maria_ferris@med.unc.edu 


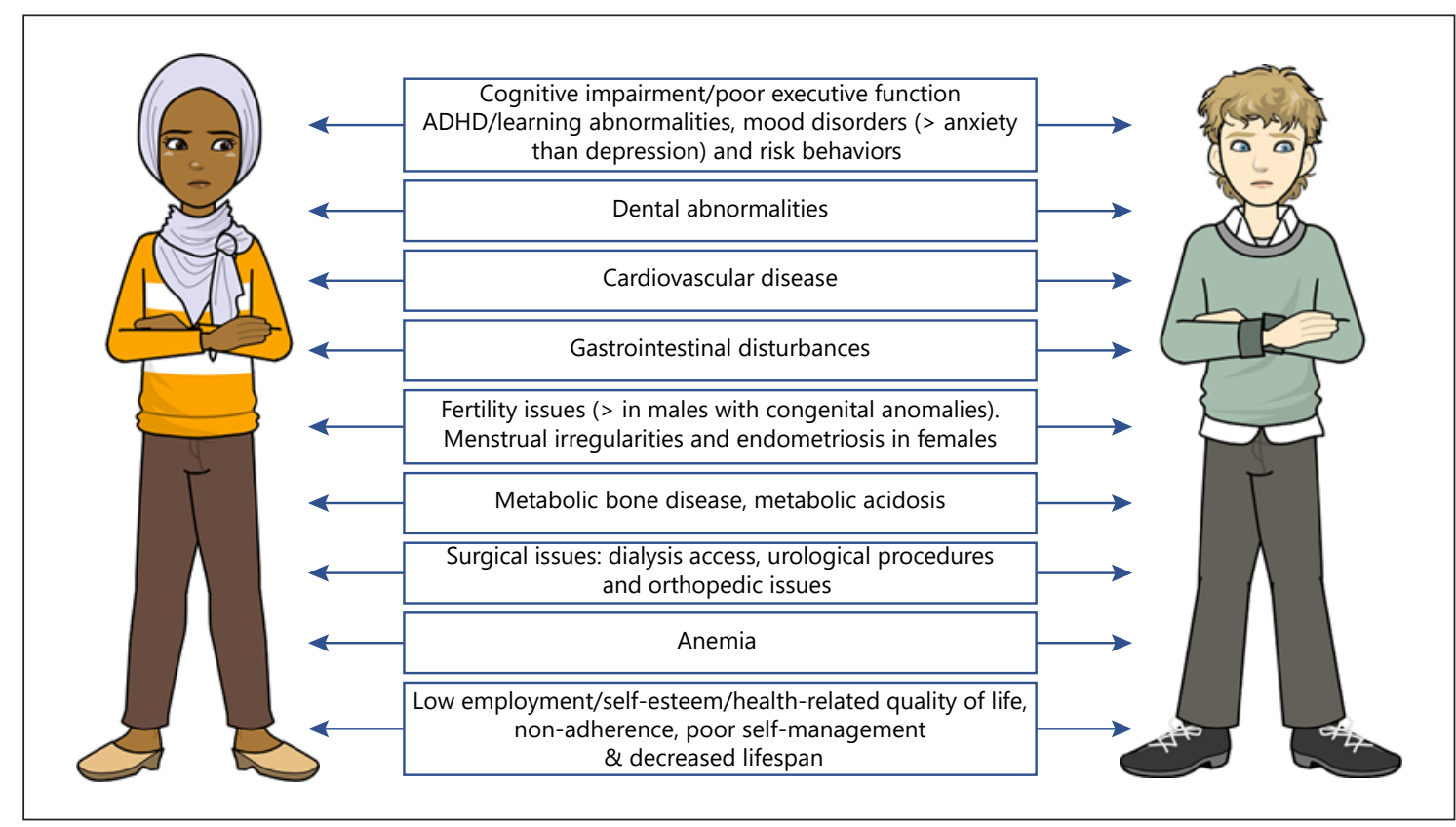

Fig. 1. Comorbidities of pediatric-onset CKD or ESKD. ESKD, end-stage kidney disease; HRQoL, health-related quality of life.

\section{Chronic Kidney Disease/End-Stage Kidney Disease in Adolescents and Young Adults}

\section{Prevalence, Etiology and Survival}

The prevalence of CKD in this age group is not well defined, and there are substantial regional, socioeconomic, and ethnic differences as well as undiagnosed cases in developing countries [1-3]. The prevalence of end-stage kidney disease (ESKD) in children and adolescents is 5560 per million of age-related population [4] but it is rising, due to an increase of congenital anomalies of the kidneys and urinary tract (CAKUT) and cancer survival [5]. The etiology of CKD/ESKD in adolescents and young adults (AYAs) varies by age with predominantly CAKUT in younger patients and glomerular conditions in older patients [6-8]. AYAs with ESKD have a 10-year survival of $>85 \%$ [9] and health-care transition (HCT) preparation from pediatric- to adult-focused care and from parentdirected to health self-management must take place, to ensure optimal patient outcomes.

\section{Unique Comorbidities}

AYAs with CKD/ESKD have unique comorbidities (Fig. 1; Table 1) that create specific challenges for patients, families, and providers as they have to manage the burden of care including: polypharmacy [10], procedures (enteral feeding, catheterizations, injections - growth hormone - or erythropoietin-stimulating agents - or dialysis), special diets, academic challenges, multiple medical appointments, and increase health-care utilization (surgeries, admissions, or emergency department visits) [11]. Other comorbidities include cardiovascular complications [12, 13], growth, mineral bone disorders [14], anemia, reproductive abnormalities, and dental conditions. These patients need close interdisciplinary collaboration to optimize their care.

\section{Cognitive Impairment, $A D H D$, and Academic and Psychological Issues}

AYAs with CKD/ESKD are more likely to have cognitive deficits and learning disabilities such as poor executive function and short attention span, and these are directly related to the disease duration $[15,16]$. ADHD is highly prevalent in patients with pediatric-onset $\mathrm{CKD} /$ ESKD and often is undiagnosed [17]. It is essential to recognize their learning challenges, ADHD and school absenteeism, and facilitate remediation [18].

In addition, social interactions with their peers and teachers may place them at risk for being labeled as "different" and/or bullying. Failure to recognize these challenges may result in behavioral and affective disorders. It is well known that emotional health is associated with 
Table 1. Comorbidities of pediatric-onset CKD or ESKD, and HCT preparation

\begin{tabular}{|c|c|c|}
\hline System & Manifestations/issues & Management to avoid complications \\
\hline Cardiovascular & Hypertension or volume overload & $\begin{array}{l}\text { Aggressive blood pressure control by height percentile if younger than } 13 \\
\text { years of age or }<130 / 80 \text { if older than } 13 \text { years of age. Monitor cardiac function. } \\
\text { If applicable, encourage fluid restriction }\end{array}$ \\
\hline \multirow[t]{2}{*}{ Sodium } & $\begin{array}{l}\text { Retention in patients with glomerular } \\
\text { conditions }\end{array}$ & $\begin{array}{l}\text { Fluid restriction and diuretics (if applicable). Thiazides in the early stages of } \\
\text { CKD and loop diuretics in later stages of CKD }\end{array}$ \\
\hline & $\begin{array}{l}\text { Wasting in patients with CAKUT and is } \\
\text { associated with poor growth }\end{array}$ & Salt supplementation from 1 to $5 \mathrm{mEq} / \mathrm{kg} /$ day \\
\hline \multirow[t]{2}{*}{ Potassium } & Hyperkalemia & Restrict potassium-rich food \\
\hline & Hypokalemia & Supplement potassium and constant monitoring to avoid hyperkalemia \\
\hline Hematological & Anemia & Maintain age-appropriate hemoglobin (target for average of $12.0 \mathrm{mg} / \mathrm{dL}$ ) \\
\hline $\begin{array}{l}\text { Mineral bone } \\
\text { abnormalities }\end{array}$ & Metabolic bone disease & $\begin{array}{l}\text { Vitamin D/calcium supplementation, phosphate binders. Avoid } \\
\text { hyperparathyroidism, high or low bone turnover. Keep bone mineral labs in } \\
\text { normal ranges for age to optimize growth }\end{array}$ \\
\hline Acid-base balance & Metabolic acidosis & Bicarbonate supplementation \\
\hline Growth & Short stature & $\begin{array}{l}\text { Optimize acidosis, metabolic bone disease, and anemia. If possible, prescribe } \\
\text { growth hormone supplementation }\end{array}$ \\
\hline Dyslipidemia & Abnormal lipid panel & $\begin{array}{l}\text { Evaluate need for fibrates or krill oil. Consider diet and lipid-lowering agents } \\
\text { in heterozygous familial hypercholesterolemia }\end{array}$ \\
\hline Dental issues & Teeth, enamel, gum, and salivary issues & Early referral to dental services. Avoid medications that affect dental health \\
\hline Psychoeducation & \multirow[t]{3}{*}{ Poor academic performance } & \multirow{3}{*}{$\begin{array}{l}\text { Foster interdisciplinary collaboration with social workers and educational } \\
\text { providers. Create care plans and facilitate school adaptation }\end{array}$} \\
\hline Cognitive impairment & & \\
\hline Academic issues & & \\
\hline
\end{tabular}

Mood disorders Anxiety Use screening tools in the clinic such as GADS Survey, RCADS child/RCADS-
parent, and PHQ-9 Surveys. Provide behavioral health services to the patients. Refer to psychological team

\begin{tabular}{lll} 
& Depression & Provide behavioral health services and medical treatment \\
\hline HRQoL & $\begin{array}{l}\text { Individual conception of happiness and } \\
\text { wellness }\end{array}$ & $\begin{array}{l}\text { Use validated questionnaires such as PROMIS or PedsQLfocused in } \\
\text { adolescents and young adults with CKD. Identify areas of improvement for } \\
\text { the patient }\end{array}$ \\
\hline Treatment adherence & $\begin{array}{l}\text { Failure or success in treatment with } \\
\text { biological and clinical manifestations }\end{array}$ & $\begin{array}{l}\text { Educational program about disease and complications, importance of } \\
\text { medications; work with parents with reminders and multidisciplinary } \\
\text { strategies }\end{array}$ \\
\hline $\begin{array}{l}\text { Diet adherence } \\
\text { Appointment adherence }\end{array}$ & $\begin{array}{l}\text { Failure or success in treatment with } \\
\text { biological and clinical manifestations }\end{array}$ & $\begin{array}{l}\text { Educational program importance of dietary restrictions, and their } \\
\text { specifications, work among family and dietitians to accommodate a suitable } \\
\text { diet (budget and cultural/religious restrictions) }\end{array}$ \\
\hline $\begin{array}{l}\text { communicate with the health-care } \\
\text { providers }\end{array}$ & $\begin{array}{l}\text { Coordinate visits with multiple providers. If electronic health records } \\
\text { available, encourage the patient/caregiver to use the patient portal for } \\
\text { communication. Use telemedicine when possible }\end{array}$ \\
\hline $\begin{array}{l}\text { Disease-specific and } \\
\text { nutrition education } \\
\text { material }\end{array}$ & $\begin{array}{l}\text { Available patient education material at high } \\
\text { literacy level }\end{array}$ & $\begin{array}{l}\text { Low-literacy tools available at the following website: www.med.unc.edu/ } \\
\text { transition. Create or adapt current patient education material to the different } \\
\text { developmental ages with a 4th-grade literacy level }\end{array}$ \\
\hline
\end{tabular}

ESKD, end-stage kidney disease; HCT, health-care transition; CAKUT, congenital anomalies of the kidneys and urinary tract. 
medical consequences that limit their health management and school performance. Hence, it is essential to inform the school personnel (counselors, teachers, social workers, and school nurses) about the academic, physical, and emotional effects of CKD/ESKD. Supporting these students in their academic performance and integrating them with their peers becomes extremely important. Communicating often with the academic team will overcome many of the barriers while maximizing learning opportunities.

Unfortunately, most AYAs do not like to disclose their health conditions [19]. Health-care providers must discuss disclosure issues in a private setting and be proactive in addressing patients' concerns. A letter can be given to the patient and parent to be delivered to the school system, stressing the point about unrecognized learning disabilities, particularly if their condition presented at younger ages [20]. Teachers need to implement technical and didactic activities that encourage the patients' participation. Teachers need to prepare, update, and make an additional effort to recognize what their students require (including an individualized education plan), making use of all available pedagogical resources to help them promote a better academic performance, adaptation and integration of the student into the group where their participation is appreciated and recognized. Flexibility, organization, and distribution of content are reasonable adjustments that should be applied, according to the student's academic progress. In addition, the educator recommendations generate favorable environments for peer support and interrelation, maintaining an optimal balance for the development of socioemotional resilience [21].

\section{Psychological Issues}

Anxiety and depression are highly prevalent among pediatric CKD patients and often are associated with a history of maternal depression and anxiety, sometimes even during pregnancy for prenatally diagnosed conditions [22]. Mood disorders can affect as many as $2 / 3$ of patients, especially in families with lower socioeconomic status [22]. In the CKD cohort, $>25 \%$ of the patients have internalizing problems, attention problems and poor adaptive skills, persistent hypertension-associated attention problems, and resulting behavioral symptoms [23].

\section{Health-Related Quality of Life}

Even with mild CKD, children report worse overall health-related quality of life, physical, school, emotional, and social functioning in comparison with healthy chil- dren [24]. Early intervention to improve linear growth and to address school functioning difficulties is recommended [24]. The ramifications of these difficulties are in part responsible for the substantial problems in early adulthood [25]. The longer the duration of ESKD, the lower the adult health-related quality of life. Former pediatric ESKD patients often cannot find a partner, live independently, or achieve gainful employment. AYAs with CKD/ESKD and low parental educational levels require optimized educational, psychologic, and social support to reach the educational level of their peers. This support should be maintained during adulthood to help them integrate into the workforce and build a family [26]. The negative impact of short stature cannot be emphasized enough [27].

\section{Adherence}

Adhering to the often complex and intense requirements of CKD/ESKD treatment is challenging. Adolescents and parents feel emotional attachment to the pediatric unit and use the support system as a tool to adherence. Once in adult care, adolescents feel out of place among the older patients, overwhelmed by the environment and the perceived lack of attention from health professionals [28]. This often results in even worse adherence and subsequent graft loss.

\section{Dental Conditions in Pediatric-Onset CKD/ESKD}

Dental and oral health is understudied in pediatric patients with CKD/ESKD. They can have decreased salivary flow (related to fluid restriction or medication side effects), abnormal saliva [29], stomatitis, gingivitis and parotitis [30, 31], altered salivary composition [32], and enamel hypoplasia. Amlodipine [33] and cyclosporine [34] are associated with substantial gingival hyperplasia. The oral pathology in CKD/ESKD may affect deciduous and/or permanent teeth and may worsen with longer disease duration and/or genetic conditions. Of interest, a systematic review of the literature revealed that dental caries is lower among pediatric patients with CKD compared to healthy controls, likely related to the effects of uremia [35].

\section{Cardiovascular Issues}

Cardiovascular complications are highly prevalent among pediatric $\mathrm{CKD}$ patients and form the major cause of premature death $[12,14,36,37]$. The mechanisms are multifactorial, including end-organ damage from hypertension [37], volume overload [38], increased peripheral resistance [38] and may be due to elevated fibroblast fac- 
tor 23 [39-41], cardiac stunning during dialysis with intradialytic hypotension $[42,43]$, and other factors. More recently, derangements of essential and toxic trace elements have been recognized. [44-47]. The changes are not limited to the heart, but there is also a high prevalence of aortic dilation [13, 48, 49]. It will be important to pay more attention to these issues to prolong the long-term survival of these patients.

\section{Gastrointestinal and Nutrition Issues}

Constipation is highly prevalent and may be related to high output kidney failure in CAKUT patients, structural problems such as Prune-belly syndrome, or neurological problems, such as in spina bifida patients. Cachexia or protein energy-wasting is common in pediatric patients with CKD/ESKD and thought to be related to systemic inflammation, endocrine disturbances, abnormal neuropeptide signaling, and poor nutritional intake [50]. These patients also often have delayed gastric emptying, resulting in changes of their oral glucose tolerance testing. Thinness has also been associated with aortic dilation [48]. Aggressive enteral nutrition causes obesity [51]. Increased body mass has been associated with decreased transplantation and increased morbidity and mortality [52].

\section{Endocrine and Fertility Issues}

Children with CKD often experience impairment of pubertal growth and delayed sexual maturation. Delayed puberty and reduced pubertal growth are most pronounced in children with preexisting severe stunting before puberty, requiring long-term dialysis treatment, and in transplanted patients with poor graft function and high glucocorticoid exposure. In pre-dialysis patients, therapeutic measures to improve pubertal growth are limited and mainly based on the preservation of kidney function and the use of growth hormone treatment [53]. There may also be subsequent fertility issues. Many men exhibit subfertility or infertility due to hypogonadism, erectile dysfunction, direct impairment of spermatogenesis with sperm toxicity, and late-stage maturational arrest causing oligospermia or azoospermia [54]. Fertility may improve post-kidney transplant, but not in all men. Males with infantile cystinosis have hypergonadotropic hypogonadism [55, 56], but testosterone replacement may not always be safe [55]. For women with CKD, contraceptive side effects are more prevalent. CKD and its therapies also affect future fertility. When conception is desired, young women with CKD must plan meticulously because an ill-timed pregnancy can result in disease progression or flare. Certain immunosuppressants like MMF and ACE inhibitors are potentially teratogenic [57, 58]. Among women with $C K D$, pregnancy risks are substantial, with up to 10-fold higher risk for preeclampsia and 6-fold higher risk for preterm delivery $[59,60]$. Pregnancy complications associated with inadequate placentation also increase maternal and newborn risks for cardiovascular morbidity/mortality and progression to kidney failure. As such, it is the obligation of every nephrologist caring for women of reproductive age to provide guidance in the choice of methods to prevent unplanned pregnancies and to choose treatments that preserve fertility [61].

\section{Metabolic Acidosis, Metabolic Bone Disease, and Growth Issues}

Pediatric CKD patients often suffer from metabolic acidosis, short stature (which in some cases may be due to sodium wasting), hyperparathyroidism, and kidney osteodystrophy. Short stature has multiple etiologies in children with CKD/ESKD including genetic/syndromic factors, parental height, delayed puberty, abnormalities in the insulin-like growth factor, poor response to natural growth hormone, water and electrolyte abnormalities (particularly sodium), prescribed steroids and anemia [62]. Some diseases such as infantile cystinosis cause profound short stature, which heavily impacts the quality of life [63]. Growth hormone therapy is an effective treatment option, but physician and patient adherence is low due to a variety of reasons [64]. This is despite the fact that growth hormone therapy in pediatric CKD patients has been demonstrated to improve final height and it does not worsen the progression of CKD nor is it associated with rejection after kidney transplantation [65]. Males especially have a very low quality of life with short stature, as was shown in a nationwide study comparing the quality of life of young adults with pediatric cancer or CKD (see Fig. 2) $[25,66]$. Patient factors (needle phobia), caregiver factors (low focus on final height), and insurance coverage are major barriers for the prescription of recombinant human growth hormone [67].

\section{Surgical Issues of CKD/ESKD}

These include urological procedures, vesicostomies, gastrostomy tubes, dialysis access (peritoneal catheters, central venous catheters, arteriovenous fistulas, or grafts), and complications such as peritonitis infections, sepsis, and thrombosis. Kidney transplant requires prolonged hospitalization and carries infectious and thrombotic 


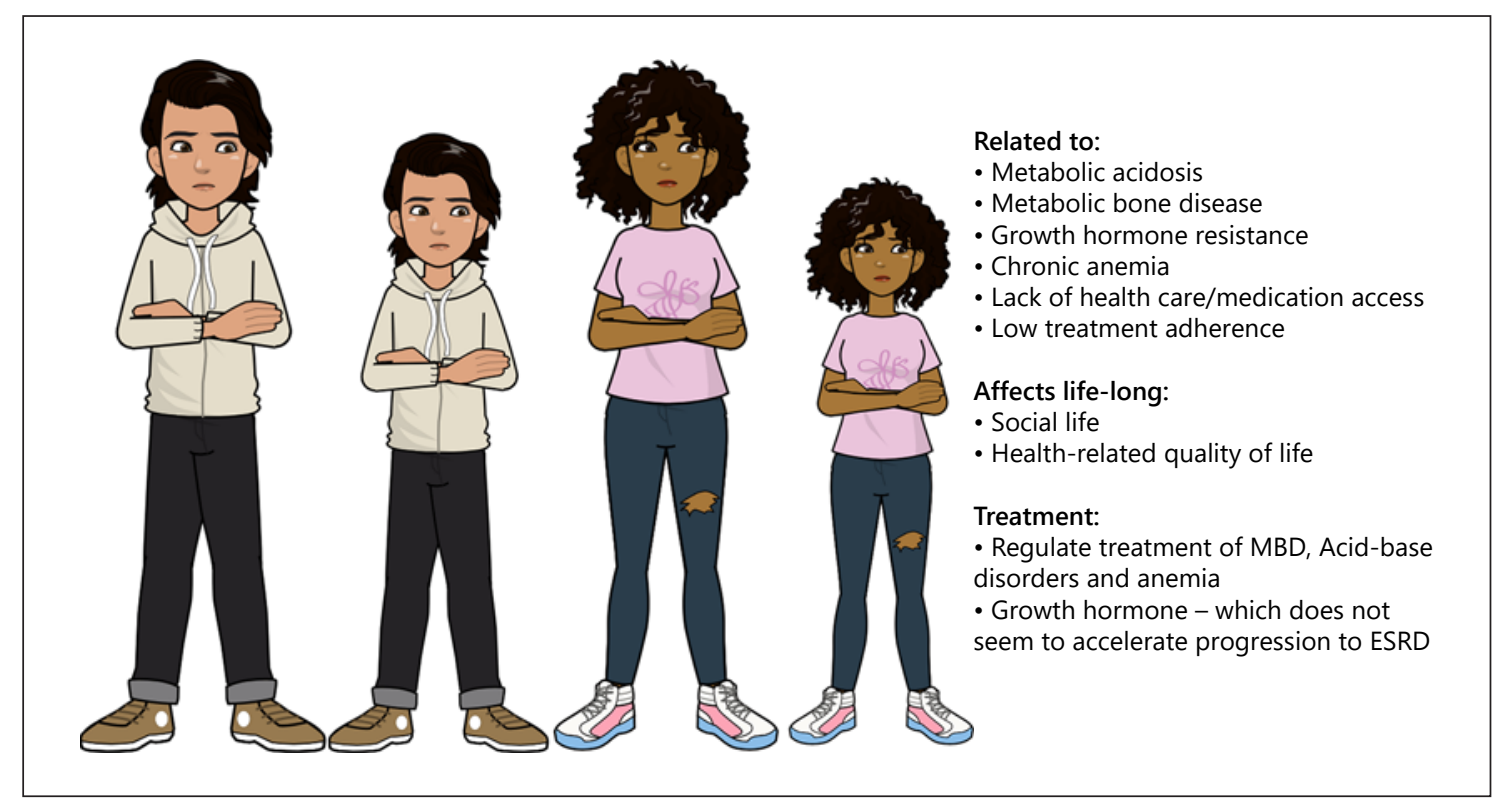

Fig. 2. Short stature in pediatric-onset CKD or ESKD. ESKD, end-stage kidney disease.

risks. Parathyroidectomy and orthopedic procedures may be needed for those with uncontrolled metabolic bone disease.

\section{Caregivers}

Caregivers not only have to perform their parenting duties but also must promote healthy family environments to allow the adaptation and to reduce frustration, anxiety and grief as much as possible. Caregiver anxiety is a major contributor to depression of the pediatric CKD patient [22]. Additionally, challenges with parenting skills affect how pediatric CKD patients grow up [23]. Caregivers may experience guilt and tendencies to spoil the children and adolescents, rather than making them responsible for their actions or delegating responsibilities of health management. Parenting style matters: permissive or indulgent education leads to inability to be successful in the adult environment, authoritarian education style yields best resilience in a competitive work environment, and authoritative education style leads to the best transition readiness [68]. Caregivers play a significant role in their child's health knowledge and management of their conditions (Table 2).

Caregiver's level of role overload (a situation in which the demands of an individual's roles are beyond their capacity to perform adequately) has been associated with poor outcomes in adolescents. We have demonstrated that caregivers with high levels of role overload may per-

Transition to Adult-Focused Health care ceive their youth as having lower self-management skills and being less ready to transition to adult-focused care, based on the parent $\operatorname{STAR}_{\mathrm{x}}$ Questionnaire [69]. Our group also has reported that adolescents prefer to learn about their health condition from their parents followed by their providers [68]. We also demonstrated that parents are at almost the same level of disease knowledge as their child, based on the parent version of the $\mathrm{TR}_{\mathrm{x}} \mathrm{ANSI}-$ TION Index [70].

\section{HCT Preparation and Self-Management}

The process of HCT from pediatric- to adult-focused services has been defined and endorsed by pediatricand adult-focused nephrology associations [71-73], and models for research and clinical practice have been proposed [74]. HCT preparation must take place both in the pediatric- and adult-focused settings, particularly since the brain is not fully developed until about 25 years of age [75]. Adolescents who prefer to learn from their parents have better adherence, while those who prefer to learn about their health from health providers have better self-efficacy and HCT preparation scores [76]. Barriers and facilitators for HCT have started to be identified in the literature and are discussed in Table 3 , along with suggestions to overcome these barriers. 
Table 2. HCT and self-management: evidence from the literature and field work

\begin{tabular}{ll}
\hline Task/skill & Issue \\
\hline HCT program & Unavailable or limited HCT program. \\
& Unclear if these services are billable
\end{tabular}

Activity

Build a transition program in combination with the adult center to improve care and awareness of the patients following guidelines $[72,73]$. Follow clinical framework [74] and billing guide in www.gottransition.org

Tools to measure HCT readiness Unclear about patient readiness in patient

Use the provider-administered/verified $\mathrm{TR}_{\mathrm{X}} \mathrm{ANSITION}$ Index [76], the self-administered $\mathrm{STAR}_{\mathrm{x}}$ Questionnaire $[77,78]$, or RTQ Survey [79]

Tools to measure HCT readiness Unclear about parent/caregiver in parent/caregiver or provider knowledge or their perception on their child's readiness

Use the provider-administered/verified $\mathrm{TR}_{\mathrm{X}} \mathrm{ANSITION}$ Index parent version [70], the self-administered $\mathrm{STAR}_{\mathrm{x}}$ Questionnaire parent version, or RTQ Survey [79] or provider survey [80]

AYA's preferred person to learn from about health condition

Parent is preferable source of health information, followed by health provider [75]

Measure [70] and understand parental knowledge about their child's disease as well as comfort teaching their child about their health and treatment

Populations at risk for poor HCT Patients of underrepresented race/ readiness ethnicities or lower socioeconomic status [82]

Self-management Showing failure or success in managing their disease from an holistic perspective

Dedicate special time and resources to ensure equity and patient safety

Encourage patients to learn about their health condition, medications, and dietary needs at an early age and continue re-enforcement of these activities. Encourage home chores by the child based on abilities. Determine parenting style [68] and burden of care [69]. Encourage parents to gradually delegate responsibilities to their child [71]

HCT, health-care transition; AYA, adolescents and young adults.

\section{Monitoring of HCT Readiness}

Tools that measure HCT readiness and have been tested in AYAs with CKD/ESKD are the $\mathrm{TR}_{\mathrm{x}} \mathrm{ANSITION}$ Index [77], a provider-administered and verified measure and the self-administered STAR $_{x}$ Questionnaire [78, 79]. We have also developed their parent-equivalent surveys (See www. med.unc.edu/transition) [69]. There is another survey for transplant patients (RTQ) [80, 81]. We administer the $\mathrm{TR}_{\mathrm{x}}$ ANSITION Index and $\mathrm{STAR}_{\mathrm{x}}$ Questionnaire annually. With longitudinal observations of over 10 years, we have documented that AYAs achieve self-management skills in their mid-20s, based on the $\mathrm{TR}_{\mathrm{x}}$ ANSITION Index [82].

\section{Equity Issues}

Language and cultural barriers among patients and caregivers need to be considered. In a sample of AYAs with chronic conditions who had public health insurance, we demonstrated that those with a high rate of disease self-management had more life-time emergency depart- ment visits, hospitalizations, and in-patient days compared to those with lower self-management skills [83]. In some jurisdictions, chronological rather than developmental age determines the timing of transfer, which may not be aligned with achieving optimal health outcomes.

\section{Pediatric-Focused Specialty and Primary Care Teams}

In many jurisdictions, HCT outcomes are poor and may even involve graft loss or exacerbation of chronic conditions, especially when sub-optimal HCT preparation takes place and patients get lost in the transfer from a more paternalistic to a self-care-oriented approach. The $\mathrm{HCT}$ process needs to be carefully planned and continued in the adult-oriented health-care systems. Communication and close collaboration between the patients, caregivers, and primary care/specialty health providers is paramount. AYA patients with CKD/ESKD are particularly challenging, as they need customized HCT preparation based on developmental characteristics in a facility that 
Table 3. Barriers and facilitators for HCT preparation based on the International and interdisciplinary HCT model [73]

\begin{tabular}{|c|c|}
\hline Barriers & Facilitators \\
\hline \multicolumn{2}{|l|}{ Patient } \\
\hline Anxiety & Acknowledge and discuss psychological support and refer to support groups when possible [22] \\
\hline Depression & Antidepressants as indicated and refer to psychiatry/psychological care [21] \\
\hline Risk behaviors/HRQoL/self-image & $\begin{array}{l}\text { Acknowledge and discuss with patient } \\
\text { Refer for psychological support }[23-25,28-33]\end{array}$ \\
\hline Low literacy & Speak with all patients/families using plain language and low-literacy terms \\
\hline Cognitive impairment/ADHD & Use cognitive remediations and treatment as needed [18] \\
\hline Low academic achievement & $\begin{array}{l}\text { Practice constant communication with educators, starting with a letter that describes the cognitive issues of CKD } \\
\text { Request evaluation for an individualized education plan }[20,25]\end{array}$ \\
\hline $\begin{array}{l}\text { Learning about their health condition } \\
\text { and diet }\end{array}$ & $\begin{array}{l}\text { Use low-literacy patient education material and offer review discussion, particularly if diagnosis was at an early } \\
\text { age. Consider using the following kidney disease and transition education tools: https://www.med.unc.edu/ } \\
\text { transition/transition-tools/ }\end{array}$ \\
\hline \multicolumn{2}{|l|}{ Caregiver } \\
\hline Caregiver anxiety & Acknowledge and discuss psychological support. Refer to support groups when possible \\
\hline Caregiver depression & Have caregiver seek psychiatric/psychological care \\
\hline Caregiver role overload & Provide strategies for the caregiver to effectively manage and delegate all duties [68] \\
\hline Parenting style of the caregiver & Counsel on effective parenting styles [67] \\
\hline Grief/guilt/catastrophizing & $\begin{array}{l}\text { Continuously acknowledge these feelings from the time of diagnosis and provide coping strategies/community } \\
\text { resources. Refer to caregiver support groups when available }\end{array}$ \\
\hline Caregiver low literacy & For all patients, regardless of education level, speak using plain language and low-literacy terms \\
\hline $\begin{array}{l}\text { Unwilling to "let go" of health } \\
\text { management }\end{array}$ & $\begin{array}{l}\text { Use caregiver HCT readiness surveys [69]. Ask caregiver to start delegating responsibilities for home chores in } \\
\text { early childhood and health management starting in early adolescent years [27] }\end{array}$ \\
\hline $\begin{array}{l}\text { Caregiver as a resource for their child's } \\
\text { health education }\end{array}$ & $\begin{array}{l}\text { Discuss with caregiver that their child will most likely come to them for health-related questions [74]. Educate } \\
\text { caregiver, offering review sessions } \\
\text { Consider using the following kidney disease and transition education tools: https://www.med.unc.edu/transition/ } \\
\text { transition-tools }\end{array}$ \\
\hline
\end{tabular}

Providers

Why is having a HCT/self-management Given the poor outcomes of unprepared patients transferred to adult-focused services (e.g., death or loss of preparation program a priority? transplant), the International Society of Nephrology and the International Pediatric Nephrology Association have identified HCT preparation as a priority for patient safety and quality improvement $[27,65,70,71,72]$

When to start and end HCT/selfmanagement preparation Start as early as possible but if limited staff, start at age 15 [81]. The age to end this preparation is in the mid-20s, as during this age, patients can self-manage their condition [80]

How to do HCT/self-management preparation Use HCT readiness surveys every 6-12 months to identify skills achieved and areas of deficits [75-78, 79] Train patients based on age and cognitive level [19]

Where do HCT/self-management preparation activities happen?

They can be done at the in-patient service or outpatient clinics Brief interventions based on deficits and age are ideal, given attention span issues

Who does the HCT/self-management All health providers during all interactions with patients. This should be an interdisciplinary and coordinated training? process [73]

Unfamiliarity with the transition process and preparation

Learn about HCT [70-72] and develop a plan (see www.gottransition.org)

Use HCT tools to measure progress and skill acquisition every 6-12 months (see www.med.unc.edu/transition)

Low trust in the adult-focused health Identify adult-focused primary care and specialty providers who are comfortable caring for AYAs with CKD/ system by the patient ESRD

Poor interdisciplinary communication Utilize discharge letters and medical passports that the patients can carry with them

Personnel issues

Identify a HCT leader who ideally can serve as a bridge to all health systems

Billing issues (in the USA)

Develop a billing plan per Got Transition (see www.gottransition.org) 
Table 3 (continued)

\begin{tabular}{ll}
\hline Barriers & Facilitators \\
\hline $\begin{array}{l}\text { System } \\
\text { Health insurance coverage }\end{array}$ & $\begin{array}{l}\text { Maximize opportunities for funding when possible. Keep in mind that those with public or no insurance (USA) } \\
\text { are at a greater risk for low transition readiness }\end{array}$ \\
\hline $\begin{array}{l}\text { Pediatric hospital age-cap policies } \\
\text { Advocate for the care of AYAs with CKD/ESKD who have unique comorbidities and special needs, so that } \\
\text { chronological age does not determine access to pediatric care }\end{array}$ \\
\hline $\begin{array}{l}\text { or ethnicity } \\
\text { AYA, adolescents and young adults; HCT, health-care transition; HRQoL, health-related quality of life; ESKD, end-stage kidney disease. }\end{array}$ \\
\hline
\end{tabular}

will optimize their quality of life. While Internal Medicine/Pediatrics specialists are particularly qualified to serve transitioning AYAs with chronic conditions, there are not enough providers with this combined training. Family practitioners and pediatric primary care providers have the benefit of long-term relationships with families, but they are also busy providers with short appointment times. As the timing of transition may coincide with moving for post-secondary education, these resources may be lost at the same time. Nonetheless, primary care providers are uniquely suited to bridge some of the needs of AYA patients during the transition period.

Table 3 depicts some of the facilitators and barriers of $\mathrm{HCT} /$ self-management preparation as reported in the literature or based on our own longitudinal transition program, at the University of North Carolina Chapel Hill, established in 2006 with collaborators in México (Hospital Infantil de México Federico Gómez), Colombia (Hospital Valle del Lili), and other countries around the world. Important barriers of HCT preparation (e.g., finding adult-focused practices that will accept these AYAs, negotiating the unfamiliar adult health-care system, and poor communication between pediatric- and adult-focused providers or different electronic health record systems), can be addressed by a dedicated interdisciplinary HCT team. The members of this HCT team need to help the patient/family feel comfortable and confident for the transfer to a new facility/team; however, the framework for an effective HCT preparation remains to be validated.

\section{Adult-Focused Team}

Adult-focused nephrologists and primary care providers are not as familiar with the unique diagnoses/comorbidities of AYAs with pediatric-onset CKD/ESKD and have less access to interdisciplinary collaborators/resources, compared to pediatric practices. In the USA, most pediatric nephrologists are in academic settings with more access to ancillary health services and have more flexibility to accept under-insured patients, whereas adult-focused nephrologists are in private practices and have less flexibility in those aspects of care. In Table 3, we have listed the facilitators to help with the continued patient education and self-management services. While not fully comprehensive, this table also lists some of the "how to do" activities for HCT/self-management preparation in clinical practice.

\section{Conclusions}

AYAs with CKD/ESKD have significant comorbidities that require close interdisciplinary collaboration between clinical, dental, psychological, and academic teams, in order to achieve successful patient and family outcomes. Taken together, patients with pediatric-onset CKD/ ESKD transitioning to adult health care are not only going through a difficult phase of their development, but may face substantial physical and psychological challenges. Those with a longer duration of CKD/ESKD or with associated syndromes are at a greater risk for cognitive impairment. Patients and caregivers may have additional anxieties, as these families face significant financial challenges and burden of care. Providers need to know about the patients' development (cognitive abnormalities, ADHD, delayed/shortened puberty, and growth failure), in addition to age-related adherence issues, to address disease-specific comorbidities. AYAs with CKD/ESKD often feel out of place in the adult practice setting, due to the great predominance of much older patients. All of these challenges mandate a structured HCT preparation program, starting in early adolescence and continuing in the adult-focused setting, to improve patient outcomes. 


\section{Acknowledgements}

We wish to thank our patients and their families for guiding us to optimize their care. We are grateful to our parents who taught us about the gift of serving others and our families who support and embrace our professional missions.

\section{Statement of Ethics}

Data were not collected from patients or study participants. No primary or original data were used for writing this work.

\section{Conflict of Interest Statement}

There are no real, potential, or perceived conflicts of interest to report related to this study. Dr. Díaz-González de Ferris has received grant support from the Renal Research Institute. This content is solely the responsibility of the authors and does not necessarily represent the official views of the Renal Research Institute.

\section{Funding Sources}

The authors did not receive any funding.

\section{Author Contributions}

This manuscript was conceived by the first and senior authors; all co-authors contributed vital intellectual content, wrote various sections related to their area of expertise, edited the manuscript, and approved the final version.

\section{References}

1 White SL, Cass A, Atkins RC, Chadban SJ. Chronic kidney disease in the general population. Adv Chronic Kidney Dis. 2005 Jan; 12(1):5-13.

2 Chartier MJ, Tangri N, Komenda P, Walld R, Koseva I, Burchill C, et al. Prevalence, sociodemographic characteristics, and comorbid health conditions in pre-dialysis chronic kidney disease: results from the Manitoba chronic kidney disease cohort. BMC Nephrol. 2018 Oct 10;19(1):255.

3 Bello AK, Ronksley PE, Tangri N, Kurzawa J, Osman MA, Singer A, et al. Prevalence and demographics of CKD in Canadian primary care practices: a cross-sectional study. Kidney Int Rep. 2019 Apr;4(4):561-70.

4 Becherucci F, Roperto RM, Materassi M, Romagnani P. Chronic kidney disease in children. Clin Kidney J. 2016 Aug;9(4):583-91.

5 Filler G, Payne RP, Orrbine E, Clifford T, Drukker A, McLaine PN. Changing trends in the referral patterns of pediatric nephrology patients. Pediatr Nephrol. 2005 May;20(5): 603-8.

6 Ferris M, Shoham DA, Pierre-Louis M, Mandhelker L, Detwiler RK, Kshirsagar AV. High prevalence of unlabeled chronic kidney disease among inpatients at a tertiary-care hospital. Am J Med Sci. 2009 Feb;337(2):93-7.

7 Ferris ME, Mahan JD. Pediatric chronic kidney disease and the process of health care transition. Semin Nephrol. 2009 Jul;29(4): 435-44.

8 Hsu RK, Powe NR. Recent trends in the prevalence of chronic kidney disease: not the same old song. Curr Opin Nephrol Hypertens. 2017 May;26(3):187-96

9 Ferris ME, Gipson DS, Kimmel PL, Eggers
PW. Trends in treatment and outcomes of survival of adolescents initiating end-stage renal disease care in the United States of America. Pediatr Nephrol. 2006 Jul;21(7):1020-6.

10 So TY, Layton JB, Bozik K, Farrington E, Gipson PE, Gibson K, et al. Cognitive pharmacy services at a pediatric nephrology and hypertension clinic. Ren Fail. 2011;33(1):19-25.

11 Blydt-Hansen TD, Pierce CB, Cai Y, Samsonov D, Massengill S, Moxey-Mims M, et al. Medication treatment complexity and adherence in children with CKD. Clin J Am Soc Nephrol. 2014 Feb;9(2):247-54.

12 Filler G. Challenges in pediatric transplantation: the impact of chronic kidney disease and cardiovascular risk factors on long-term outcomes and recommended management strategies. Pediatr Transplant. 2011 Feb;15(1):25-31.

13 Surak A, Filler G, Sharma AP, Torres Canchala LA, Grattan M. Lower prevalence of aortic dilatation among preemptive pediatric renal transplant recipients: a cross-sectional cohort study. Pediatr Transplant. 2020 Aug; 24(5):e13716.

14 Hussein R, Alvarez-Elías AC, Topping A, Raimann JG, Filler G, Yousif D, et al. A crosssectional study of growth and metabolic bone disease in a pediatric global cohort undergoing chronic hemodialysis. J Pediatr. 2018 Nov; 202:171-e3.

15 Javalkar K, Rak E, Phillips A, Haberman C, Ferris M, Van Tilburg M. Predictors of caregiver burden among mothers of children with chronic conditions. Children. 2017 May 16; 4(5):39.

16 Hartung EA, Erus G, Jawad AF, Laney N, Doshi JJ, Hooper SR, et al. Brain magnetic resonance imaging findings in children and young adults with CKD. Am J Kidney Dis. 2018 Sep;72(3):349-59.
17 Eisenhauer GL, Arnold WC, Livingston RL. Identifying psychiatric disorders in children with renal disease. South Med J. 1988 May; 81(5):572-6.

18 Javalkar K, Ferris ME, Cuttance J, Hooper SR Cognitive remediation in pediatric chronic kidney disease and end-stage kidney disease: rationale, candidate interventions, and applicability. Pediatr Nephrol. 2017 Nov;32(11): 2027-35.

19 Kaushansky D, Cox J, Dodson C, McNeeley M, Kumar S, Iverson E. Living a secret: disclosure among adolescents and young adults with chronic illnesses. Chronic Illn. 2017 Mar;13(1):49-61.

20 Slickers J, Duquette P, Hooper S, Gipson D. Clinical predictors of neurocognitive deficits in children with chronic kidney disease. Pediatr Nephrol. 2007 Apr;22(4):565-72.

21 Hacia la inclusion y el logro de los aprendizajes en el alumn@ con necesidades de atencion espcifica y focalizada. Translation: towards the inclusion and achievement of the students with specific and focused needs. Monterrey, Mexico: Universidad Pedagogica Nacional (UPN).

22 Rodriguez Cuellar CI, García de la Puente S, Hernández Moraria J, Bojórquez Ochoa A, Filler G, Zaltzman Grishevich S. High depression rates among pediatric renal replacement therapy patients: a cross-sectional study. Pediatr Transplant. 2019 Dec;23(8):e13591.

23 Johnson RJ, Gerson AC, Harshman LA, Matheson MB, Shinnar S, Lande MB, et al. A longitudinal examination of parent-reported emotional-behavioral functioning of children with mild to moderate chronic kidney disease. Pediatr Nephrol. 2020 Jul;35(7):1287-95. 
24 Gerson AC, Wentz A, Abraham AG, Mendley SR, Hooper SR, Butler RW, et al. Health-related quality of life of children with mild to moderate chronic kidney disease. Pediatrics. 2010 Feb;125(2):e349-57.

25 Enden K, Tainio J, Jalanko H, Jahnukainen K, Jahnukainen $\mathrm{T}$. Lower quality of life in young men after pediatric kidney transplantation when compared to healthy controls and survivors of childhood leukemia-a cross-sectional study. Transpl Int. 2018 Feb;31(2):157-64.

26 Mellerio H, Alberti C, Labèguerie M, Andriss B, Savoye E, Lassalle M, et al. Adult social and professional outcomes of pediatric renal transplant recipients. Transplantation. 2014 Jan 27;97(2):196-205.

27 Al-Uzri A, Matheson M, Gipson DS, Mendley SR, Hooper SR, Yadin O, et al. The impact of short stature on health-related quality of life in children with chronic kidney disease. J Pediatr. 2013 Sep;163(3):736-e1.

28 Crawford K, Wilson C, Low JK, Manias E, Williams A. Transitioning adolescents to adult nephrology care: a systematic review of the experiences of adolescents, parents, and health professionals. Pediatr Nephrol. 2020 Apr;35(4):555-67.

29 Martins C, Siqueira WL, Guimarães Primo LS. Oral and salivary flow characteristics of a group of Brazilian children and adolescents with chronic renal failure. Pediatr Nephrol. 2008 Apr;23(4):619-24.

30 Al-Nowaiser A, Roberts GJ, Trompeter RS, Wilson M, Lucas VS. Oral health in children with chronic renal failure. Pediatr Nephrol. 2003 Jan;18(1):39-45.

31 Davidovich E, Schwarz Z, Davidovitch M, Eidelman E, Bimstein E. Oral findings and periodontal status in children, adolescents and young adults suffering from renal failure. Clin Periodontol. 2005 Oct;32(10):1076-82.

32 Epstein SR, Mandel I, Scopp IW. Salivary composition and calculus formation in patients undergoing hemodialysis. J Periodontol. 1980 Jun;51(6):336-8.

33 Silverstein DM, Palmer J, Baluarte HJ, Brass C, Conley SB, Polinsky MS. Use of calciumchannel blockers in pediatric renal transplant recipients. Pediatr Transplant. 1999 Nov; 3(4):288-92.

34 Salman BN, Vahabi S, Movaghar SE, Mahjour F. Proliferative and inductive effects of cyclosporine a on gingival fibroblast of child and adult. Dent Res J. 2013 Jan;10(1):52-8.

35 Andrade MR, Antunes LA, Soares RM, Leão AT, Maia LC, Primo LG. Lower dental caries prevalence associated to chronic kidney disease: a systematic review. Pediatr Nephrol. 2014 May;29(5):771-8.

36 Filler G, Huang SH. Progress in pediatric kidney transplantation. Ther Drug Monit. 2010 Jun;32(3):250-2.

37 Johnson JN, Filler G. The importance of cardiovascular disease in pediatric transplantation and its link to the kidneys. Pediatr Transplant. 2018 May;22(3):e13146.
38 Altamirano-Diaz L, Kassay AD, Serajelahi B, McIntyre CW, Filler G, Kharche SR. Arterial hypertension and unusual ascending aortic dilatation in a neonate with acute kidney injury: mechanistic computer modeling. Front Physiol. 2019;10:1391.

39 Faul C. Fibroblast growth factor 23 and the heart. Curr Opin Nephrol Hypertens. 2012 Jul;21(4):369-75.

40 Filler G, McIntyre C. Is fibroblast growth factor 23 the new biomarker for cardiovascular mortality in chronic kidney disease patients? Am J Nephrol. 2017;45(2):146-8.

41 Liu D, Alvarez-Elías AC, Wile B, Belostotsky V, Filler G. Deviations from the expected relationship between serum FGF23 and other markers in children with CKD: a cross-sectional study. BMC Nephrol. 2017 Jun 28; 18(1):204.

42 Huang SH, Filler G, Lindsay R, McIntyre CW. Euvolemia in hemodialysis patients: a potentially dangerous goal? Semin Dial. 2015 Jan; 28(1):1-5.

43 Marants R, Qirjazi E, Grant CJ, Lee TY, McIntyre CW. Renal perfusion during hemodialysis: intradialytic blood flow decline and effects of dialysate cooling. J Am Soc Nephrol. 2019 Jun;30(6): 1086-95.

44 Filler G, Roach E, Yasin A, Sharma AP, Blake PG, Yang L. High prevalence of elevated lead levels in pediatric dialysis patients. Pediatr Nephrol. 2012 Sep;27(9):1551-6.

45 Filler G, Belostotsky V, Kobrzynski M, Huang SS, Yang L. High prevalence of elevated molybdenum levels in pediatric CKD patients. a cross-sectional and longitudinal study. Clin Nephrol. 2017 Aug;88(8):79-85.

46 Filler G, Kobrzynski M, Sidhu HK, Belostotsky V, Huang SS, McIntyre C, et al. A crosssectional study measuring vanadium and chromium levels in paediatric patients with CKD. BMJ Open. 2017 Jun 6;7(5):e014821.

47 Filler G, McIntyre C. Chromium: rise and shine in peritoneal dialysis patients? Perit Dial Int. 2019 Jul;39(4):320-2.

48 Kaddourah A, Uthup S, Madueme P, O’Rourke M, Hooper DK, Taylor MD, et al. Prevalence and predictors of aortic dilation as a novel cardiovascular complication in children with end-stage renal disease. Clin Nephrol. 2015 May;83(5):262-71.

49 Madueme PC, Ng DK, Guju L, Longshore L, Moore V, Jefferies L, et al. Aortic dilatation in children with mild to moderate chronic kidney disease. Pediatr Nephrol. 2020 Jun;35(6): 1023-31.

50 Mak RH, Cheung WW, Zhan JY, Shen Q, Foster BJ. Cachexia and protein-energy wasting in children with chronic kidney disease. Pediatr Nephrol. 2012 Feb;27(2):173-81.

51 Rees L, Mak RH. Nutrition and growth in children with chronic kidney disease. Nat Rev Nephrol. 2011 Sep 27;7(11):615-23.
$52 \mathrm{Ku} \mathrm{E}$, Glidden DV, Hsu CY, Portale AA, Grimes B, Johansen KL. Association of body mass index with patient-centered outcomes in children with ESRD. J Am Soc Nephrol. 2016 Feb;27(2):551-8.

53 Haffner D, Zivicnjak M. Pubertal development in children with chronic kidney disease. Pediatr Nephrol. 2017 Jun;32(6):949-64.

54 Lundy SD, Vij SC. Male infertility in renal failure and transplantation. Transl Androl Urol. 2019 Apr;8(2):173-81.

55 Filler G, Ramsaroop A, Stein R, Grant C, Marants $\mathrm{R}$, So $\mathrm{A}$, et al. Is testosterone detrimental to renal function? Kidney Int Rep. 2016 Nov; 1(4):306-10.

56 Veys KR, D’Hauwers KW, Van Dongen AJCM, Janssen MC, Besouw MTP, Goossens E, et al. First successful conception induced by a male cystinosis patient. JIMD Rep. 2018;38: $1-6$.

57 Filler G, Wong H, Condello AS, Charbonneau C, Sinclair B, Kovesi T, et al. Early dialysis in a neonate with intrauterine lisinopril exposure. Arch Dis Child Fetal Neonatal Ed. 2003 Mar;88(2):F154-6.

58 Perez-Aytes A, Marin-Reina P, Boso V, Ledo A, Carey JC, Vento M. Mycophenolate mofetil embryopathy: a newly recognized teratogenic syndrome. Eur J Med Genet. 2017 Jan;60(1): $16-21$.

59 Barrett PM, McCarthy FP, Evans M, Kublickas M, Perry IJ, Stenvinkel P, et al. Hypertensive disorders of pregnancy and the risk of chronic kidney disease: a Swedish registrybased cohort study. PLoS Med. 2020 Aug; 17(8):e1003255.

60 Ferreira RC, Fragoso MBT, Dos Santos Tenório MC, Silva JVF, Bueno NB, Goulart MOF, et al. Pre-eclampsia is associated with later kidney chronic disease and end-stage renal disease: systematic review and meta-analysis of observational studies. Pregnancy Hypertens. $2020 \mathrm{Jul}$ 28;22:71-85.

61 Burgner A, Hladunewich MA. Women's reproductive health for the nephrologist. Am J Kidney Dis. 2019 Nov;74(5):675-81.

62 Drube J, Wan M, Bonthuis M, Wühl E, Bacchetta J, Santos F, et al. Clinical practice recommendations for growth hormone treatment in children with chronic kidney disease. Nat Rev Nephrol. 2019 Sep;15(9):577-89.

63 Beinart N, Hackett RA, Graham CD, Weinman J, Ostermann M. Mood and illness experiences of adults with cystinosis. Ren Fail. 2015 Jun;5(37):835-9

64 Mahan JD, Warady BA, Consensus C. Assessment and treatment of short stature in pediatric patients with chronic kidney disease: a consensus statement. Pediatr Nephrol. 2006 Jul;21(7):917-30.

65 Bizzarri C, Lonero A, Delvecchio M, Cavallo L, Faienza MF, Giordano M, et al. Growth hormone treatment improves final height and nutritional status of children with chronic kidney disease and growth deceleration. J Endocrinol Invest. 2018 Mar;41(3):325-31. 
66 Filler G, Diaz-Gonzalez de Ferris M. We have to do more for former paediatric renal transplant recipients!. Transpl Int. 2018 Feb;31(2): $152-4$.

67 Greenbaum LA, Hidalgo G, Chand D, Chiang M, Dell K, Kump T, et al. Obstacles to the prescribing of growth hormone in children with chronic kidney disease. Pediatr Nephrol. 2008 Sep;23(9):1531-5.

68 Bagley K, Ferris M, Javalkar K, Nazareth M, Phillips A, Van Tilburg M. Parenting style and transition readiness among adolescents and young adults with chronic kidney disease. Pharm Sci. 2016;531.

69 Hart LC, Van Tilburg MAL, Campbell R Jr, Faldowski RA, Nazareth M, Ndugga M, et al. Association of youth health care transition readiness to role overload among parents of children with chronic illness. Child Care Health Dev. 2019 Jul;45(4):577-84.

70 Hart L, D-GdF M, Nazareth M, Faldowski RA, Rak E, Hooper S, et al. Evaluation of the TRXANSITION index: parent version for assessment of readiness to transition to adult care among youth with chronic conditions. J Child Healthcare. 2020.

71 American Academy of Pediatrics, American Academy of Family Physicians, American College of Physicians, Transitions Clinical Report Authoring Group; Cooley WC, Sagerman PJ. Supporting the health care transition from adolescence to adulthood in the medical home. Pediatrics. 2011 Jul;128(1):182-200.
72 Watson AR, Harden P, Ferris M, Kerr PG, Mahan J, Ramzy MF. Transition from pediatric to adult renal services: a consensus statement by the International Society of Nephrology (ISN) and the International Pediatric Nephrology Association (IPNA). Pediatr Nephrol. 2011 Oct;26(10):1753-7.

73 Watson AR, Harden PN, Ferris ME, Kerr PG, Mahan JD, Ramzy MF, et al. Transition from pediatric to adult renal services: a consensus statement by the International Society of $\mathrm{Ne}$ phrology (ISN) and the International Pediatric Nephrology Association (IPNA). Kidney Int. 2011 Oct;80(7):704-7.

74 Betz CL, Ferris ME, Woodward JF, Okumura MJ, Jan S, Wood DL. The health care transition research consortium health care transition model: a framework for research and practice. J Pediatr Rehabil Med. 2014;7(1):315.

75 Lenroot RK, Giedd JN. Brain development in children and adolescents: insights from anatomical magnetic resonance imaging. Neurosci Biobehav Rev. 2006;30(6):718-29.

76 Johnson MA, Javalkar K, van Tilburg M, Haberman C, Rak E, Ferris ME. The relationship of transition readiness, self-efficacy, and adherence to preferred health learning method by youths with chronic conditions. J Pediatr Nurs. 2015 Sep-Oct;30(5):e83-90.

77 Ferris ME, Harward DH, Bickford K, Layton JB, Ferris MT, Hogan SL, et al. A clinical tool to measure the components of health-care transition from pediatric care to adult care: the UNC TR(x)ANSITION scale. Ren Fail. 2012;34(6):744-53.
78 Cohen SE, Hooper SR, Javalkar K, Haberman C, Fenton N, Lai H, et al. Self-management and transition readiness assessment: concurrent, predictive and discriminant validation of the STARx questionnaire. J Pediatr Nurs. 2015 Sep-Oct;30(5):668-76.

79 Ferris M, Cohen S, Haberman C, Javalkar K, Massengill S, Mahan JD, et al. Self-management and transition readiness assessment: development, reliability, and factor structure of the STARx questionnaire. J Pediatr Nurs. 2015 Sep-Oct;30(5):691-9.

80 Gilleland J, Amaral S, Mee L, Blount R. Getting ready to leave: transition readiness in adolescent kidney transplant recipients. J Pediatr Psychol. 2012 Jan-Feb;37(1):85-96.

81 Marchak JG, Reed-Knight B, Amaral S, Mee L, Blount RL. Providers' assessment of transition readiness among adolescent and young adult kidney transplant recipients. Pediatr Transplant. 2015 Dec;19(8):849-57.

82 Zhong Y, Gilleskie DB, van Tilburg MAL, Hooper SR, Rak E, Javalkar K, et al. Longitudinal self-management and/or transition readiness per the TRxANSITION index among patients with chronic conditions in pediatric or adult care settings. J Pediatr. 2018 Dec;203:361-e1.

83 Phillips GA, Fenton N, Cohen S, Javalkar K, Ferris M. Self-management and health care use in an adolescent and young adult medicaid population with differing chronic illnesses. Prev Chronic Dis. 2015 Jul 2;12:E103. 